\title{
AN EPIDEMIOLOGICAL ANALYSIS OF SOCIOECONOMIC RISK FACTORS AMONG PATIENTS OF RHEUMATIC HEART DISEASE, ISLAMABAD, PAKISTAN
}

\author{
Zafar Hayat Maken', Faizan Ahmed², Ferogh-e-Elahi' ${ }^{2}$ Ali Arumghan², Mehar $^{2}$, Khatija $^{2}$
}

Department of Community Medicine, Federal Medical \& Dental College Islamabad

Corresponding Author: Dr. Zafar Hayat Maken Associate Professor (Community Medicine) Federal Medical \& Dental College, Islamabad, drzafarmaken@gmail.com, 0332-2566777, 051-9255903, 'Associate Professor, Department of Community Medicine, FM\&DC, ${ }^{2}$ Students 4 th year FM\&DC

\begin{abstract}
Background: Rheumatic Heart Disease (RHD) is a disease of developing countries where it inflects significant burden dis-proportionality. We investigated the role of socio-economic and environmental risk factors for RHD.

Methods:-This was descriptive cross-sectional conducted at Pakistan Institute of Medical Sciences Islamabad by including the patients coming to cardiology out door patient department through convenient sampling technique. Study was approved from ethical committee of Pakistan institute of Medical Sciences Islamabad and written consent was taken prior to start the interview.

Results: In this study, the average age of patient with rheumatic heart disease was 29.4 years, male predominance of patients was observed. $67 \%$ of subjects had income below Rs. 20,000 . Average BMI of subjects was $22.4 \pm 4.04$. It was observed that $75.25 \%$ of people lived in houses with an area of less than 5 marla. Average area of house was found to be $5.12 \pm 2.8$ marla. Overcrowding was noticed in $60.8 \%$ of the subjects.

Conclusion: There is a high prevalence of RHD and Acute Rheumatic Fever (ARF) in Pakistan. The major findings of this study were that Overcrowding, poor hygienic conditions, low socio-economic status, are major risk factors for RHD. In order to address this alarming situation, platforms like Pakistan Pediatric Cardiac Society and Pakistan Pediatric Association need to be mobilized for health promotion regarding awareness of the disease.
\end{abstract}

Key words: Acute Rheumatic Fever, Rheumatic Heart Disease, risk factors, developing country.

\section{Introduction:}

Rheumatic heart disease is among the most prevalent heart disease in developing countries. Studies conducted in sub Saharan Africa suggest that RHD and Acute Rheumatic Fever (ARF) affect about 16 million people worldwide, with over $70 \%$ in Sub-Saharan Africa where the prevalence of RHD is found to be between 6.5 to 30 per1000 people. In Pakistan although sufficient data is not available to determine its prevalence nationwide but researches carried out in 2014 prevalence of RHD in Pakistan is 22/1000[1] as compared to local studied performed in India 5.4/1000 and $1.2 / 1000$ in Bangladesh [2,3]. Which is very alarming compared to the prevalence of RHD in Bangladesh and India [3].

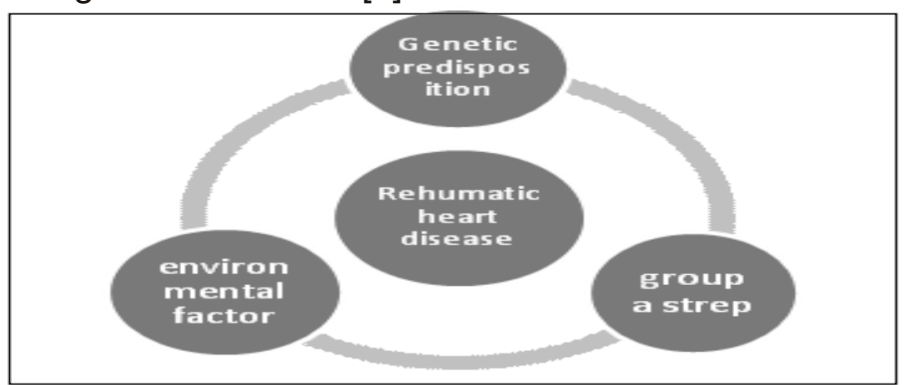

Figure 1. Factors in development of RHD
Fig.1: This relationship cycle suggests the relationship of different factors in the pathogenesis of RHD.

Pathogenesis of RHD is complex, it is caused by interplay of three factors Genetic predisposition, group A streptococcal infection and a host of environmental factors [4]. The main culprit of this immune mediated disease is Group A streptococcus Lancefield positive Rheumatogenic strain which initially causes exudative tonsillitis which is most often undertreated [4]. Genetic factors yet remain to be identified. But worldwide extensive research is being done on the socioeconomic and environmental factors e.g. overcrowding, poor health, malnutrition, poor housing. Studies conducted in Baltimore in the 1960s found out that the rate of Acute Rheumatic fever was increased as the no of people in houses increased [5]. After that many new study designs were proposed and implemented to prove similar relationship and similar positive relationship was obtained. [6,7]. The burden of heart related diseases in Pakistan is still a major cause of vulvular heart disease [8].

\section{Methodology:}

The study was cross sectional type of carried out at the cardiology unit of Pakistan institute of medical sciences, Islamabad from April 2016 to September 2016. 97 
random subjects between the age group of 5 years to 40 years were selected from pre-op,post-op and OPD. Informed consent was taken and convenience sampling was done. Patients were identified and diagnosed to have Rheumatic heart disease by history, physical examination (murmurs), lab tests and most importantly Echocardiography. Echocardiography was done according to standard criteria; briefly standard transthoracic echocardiography was performed. Mitral valve stenosis was diagnosed by two-dimensional echocardiography and hemodynamic evidence. Rheumatic heart disease as an outcome; the following independent variables were analyzed and documented; age, gender, income, height, weight, BMI of subject, number of people per house, area of house and overcrowding, hygienic conditions were assessed i.e. hand washing frequency, bathing frequency and presence of toilet facility, number of people per house and overcrowding. All of subjects or their close relatives were asked to fill a questionnaire of socioeconomic and environmental factors keeping in view the confidentiality of the subject.

\section{Results:}

Considering anthropometric values mean height was found to be $5.43 \mathrm{ft}$. Average weight was found out to be $61.51 \mathrm{~kg}$. Average BMI calculated was 22.3. Considering hygienic conditions, average hand washing frequency of subjects was 2.5 times a day. And bathing frequency of subjects was observed to be 3.5 times/week. According to our income scale groups $61.9 \%$ of people had income below Rs. $4,000-20,000$ i.e (36-181 USD) and $26.7 \%$ of people had income between Rs. 20,000-100,000 i.e. (181-909 USD) and $3.8 \%$ of people had income above Rs. 100,000 i.e. above 909 USD.

\section{Table 1: Study variables with mean and SD.}

\begin{tabular}{|l|c|c|}
\hline \multicolumn{1}{|c|}{ VARIABLES } & MEAN & $\begin{array}{c}\text { STD. } \\
\text { DEVIATION }\end{array}$ \\
\hline Age divided in groups & 29.4 & 2.9 \\
\hline Number of people living in house & 6.40 & 2.39 \\
\hline Number of rooms in house & 2.77 & 1.42 \\
\hline Area of house (Marlas) & 5.1237 & 2.80 \\
\hline No of washroom in the house & 1.40 & .687 \\
\hline Height of subject & 65.19 & 4.86 \\
\hline Weight of subject & 61.51 & 13.15 \\
\hline Hand washing frequency of subject & 2.53 & 1.04 \\
\hline Bathing frequency of subject & 3.50 & 1.68 \\
\hline BMl of subject & 22.3130 & 4.04 \\
\hline Mitral stenosis present (\%) & 51.5 & - \\
\hline Mitral regurgitation present (\%) & 39.2 & - \\
\hline Aortic stenosis present (\%) & 67 & - \\
\hline No of echoes performed & 2.08 & 1.07 \\
\hline
\end{tabular}

Average income per family was only Rs. 29,000 per month i.e. less than 263USD/month. Mean age of presentation was 29.4. Average area of house in Marla (1 marla $=272.251 \mathrm{sq} \mathrm{ft})$ was 5.1. Average rooms per house were 2.77 and average no people living per house were 6.4 . It was observed that $75.25 \%$ of people lived in houses with an area of less than 5 marla. In different areas, there was overcrowding in $60.8 \%$ of the subjects (we defined overcrowding as more than 2 people living per room). No of echoes performed per subject were 2.08 times. Mitral regurgitation was present in $39.2 \%$ of subjects. Mitral stenosis was observed in $51.5 \%$ of patients .Aortic stenosis was observed in $67 \%$ of patients.

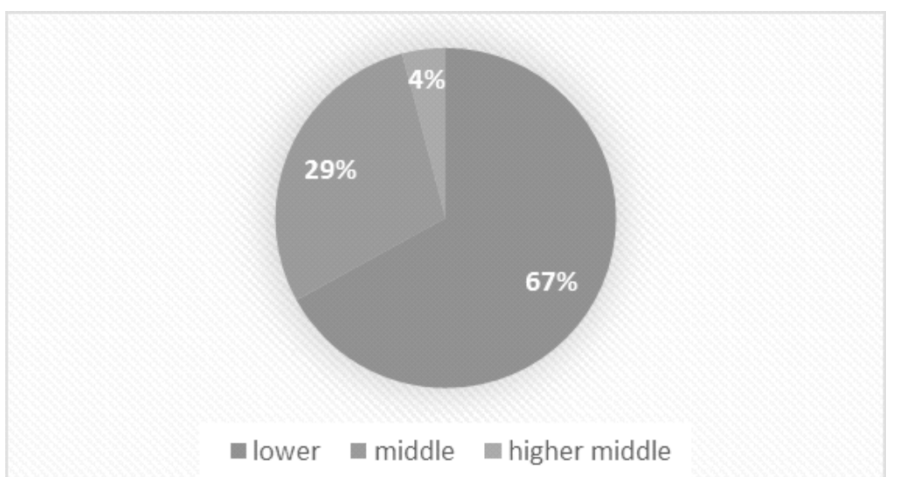

Figure 2: This pie chart shows the percentage of subjects and their income levels.

\section{Discussion:}

Rheumatic heart disease is endemic in Pakistan $[8,9]$ although the data is a bit sketchy at the moment due to lack of proper researches in Pakistan but the prevalent of RHD in Pakistan is 22/1000[3] as compared to local studied performed in India 5.4/1000 and 1.2/1000 in Bangladesh $[2,3]$. In this study we found out that average area of house in Marla ( $1 \mathrm{marla}=272.251 \mathrm{sq} \mathrm{ft}$ ) was 5.1. Average rooms per house were 2.77 and average no people living per house were 6.4. In different areas, there was overcrowding in $60.8 \%$ of the subjects (we defined overcrowding as more than 2 people living per room). And these results were consistent with the finding of overcrowding. This is because congestive living spaces lead to increases transmission of airborne pathogens and direct oral transmission also becomes a possible route of infection. In 1996, 1249 cases of ARF were assessed in an ecological study and a positive relationship between overcrowding and RHD was found out [10]. This study highlights the same pathognomonic importance of overcrowding with RHD. Although RHD is generally been linked to poverty, but in actual poverty is the proxy marker of overcrowding and overcrowding leads to RHD pathogenesis as explained earlier [11]. Our study elucidate that on income scale groups $61.9 \%$ of people had income below 4000-20000 Pakistani rupeese. A recent research in Uganda showed that there is a recent trend towards RHD when the community income level drops below 50-99.5 USD [12]. Dobson et al performed a case control study in Fiji with $80 \mathrm{RHD}$ cases and 80 control cases, and found an increasing trend towards RHD with poor hosing quality [13]. In USA re-emergence of RHD in the intermountain region of the United States [14], [15] and a high prevalence of RHD in 
Italian army recruits, both developed nations in the 1980 s, had strong association with overcrowding. With the context of RHD pathogenesis in our study we took the liberty of asking our patients the frequency and type of hand washing technique that they employed and how frequently they took a bath [16, 17]. Although it is a stated principle that poor personal hygiene in the basis of all infections transmission. In this study average hand washing frequency of subjects was 2.5 times a day and bathing frequency of subjects was observed to be 3.5 times/week [18]. We tried to keep essence of our study as practical as possible but in our short duration of time we were unable to visit the houses to assess the living standards of patient in person, as the disease pathogenesis is known to take 5 to 15 years to develop. And secondly the area and design of houses was not included in this study. Furthermore, in developing countries, income is generally low across the board and majority of people are in the informal sector, making it difficult to ascertain their actual level of income $[19,20]$.

\section{References:}

1. Sliwa KMA. Forgotten cardiovascular diseases in Africa. Clinical Research in Cardiology. 2009;99(2):65-74.

2. Grover A, Vijayvergiya R, Thingam ST. Burden of Rheumatic and Congenital Heart Disease in India: Lowest Estimate Based on the 2001 Census. Indian Heart J 2002; 54:104-7.

3. Ahmed J, Mostafa Zaman M, Manzur Hassan MM. Prevalence of rheumatic fever and rheumatic heart disease in rural Bangladesh. Trop Doct 2005; 35:160-1.

4. Kumar VRobbins S. Robbins basic pathology. Philadelphia, PA: Saunders/Elsevier; 2007.

5. Gordis L, Lilienfeld A, Rodriguez R (1969) Studies in the epidemiology and preventability of rheumatic fever. II. Socio-economic factors and the incidence of acute attacks. J Chronic Dis 21:655-666.

6. Vlajinac H, Adanja B, Jarebinski M (1989) Socioeconomic factors and rheumatic fever occurrence. Differences between patients with and without frequent sore throat. J Hyg Epidemiol Microbiol Immunol 33:471-476.

7. 19. Valjinac H, Adanja B, Marinkovic J, Jarebinski M (1991) Influence of Socio-economic and other factors on rheumatic fever occurrence. Eur $\mathrm{J}$ Epidemiol 7:702-704.

8. Anon. WHO Cardiovascular Diseases Unit. WHO program for the prevention of rheumatic fever/ rheumatic heart disease in 16 developing countries: report from phase I (1986-1990) Bull World Health Organ 1992; 70:213-8.

9. Eisenberg MJ. Rheumatic heart disease in the developing world: prevalence, prevention and control. Eur Heart J 1993; 14:122-8.

10. Jaine R, Baker M, Venugopal K (2011) Acute rheumatic fever associated with household crowding in a developed country. Pediatr Infect Dis J 30: 315-319.

11. Beg D, Younas D, Asma CD. Rheumatic Heart Disease; Socio-Economic And Environmental Risk Factors For Acute Rheumatic Fever (Arf) And Rheumatic Heart Disease (Rhd) Patients In Pakistan. The Professional Medical Journal. 2016;23(03):324-327.

12. 5. Okello E, Kakande B, Sebatta E, Kayima J, Kuteesa M, Mutatina B et al. Socioeconomic and Environmental Risk Factors among Rheumatic Heart Disease Patients in Uganda. PLoS ONE. 2012;7(8).

13. 6. Dobson J, Steer A, Colquhoun S, Kado J. Environmental Factors and Rheumatic Heart Disease in Fiji. Pediatric Cardiology. 2011;33(2):332-336.

14. Veasy LG, Wiedmeier SE, Ormond GS, Ruttenberg HD, Boucek MM, et al. (1990) Resurgence of acute rheumatic fever in the intermoutain area of the United States. New Engl J Med 8: 421-427.

15. Kaplan EL, John DR, Cleary PP (1989) Group A streptococcal serotypes isolated from patients and sibling contacts during the resurgence of rheumatic fever in the United States in themid 1980s. J Infect Dis 159: 101-103.

16. Cheng TO (2009) How much of the recent decline in rheumatic heart disease in China can be explained by changes in cardiovascular risk factors? Int $\mathrm{J}$ Cardiol 3: 132.

17. Akhtar N, Sadiq M, Chagani H, Hafeez A, Rizvi FH, Mehboob M. Guidelines for prevention of Rheumatic fever and rheumatic heart disease. Pak $\mathrm{J}$ 2004; 15:136-48.

C a r d i o

18. 7. Rizvi SF, Khan MA, Kundi A, Marsh DR, Samad A, Pasha O. Status of Rheumatic heart disease in rural Pakistan. Heart 2004; 90:394-9.

19. Krause MR. The influence of infection on the geography of heart disease. Circulation 1979; 60:972-6.4. Rose A.G. Etiology of valvular heart disease. Curr Opin Cardiol 1996; 11:98-113.

20. Aziz K. Incidence of heart disease in children at the National institute of cardiovascular diseases. J Pak Med Assoc 1984; 34:300-5. 